\title{
Aqueous Processing of Low-Band-Gap Polymer Solar Cells Using Roll-to-Roll Methods
}

Andersen, Thomas Rieks; Larsen-Olsen, Thue Trofod; Andreasen, Birgitta; Böttiger, Arvid P.L.; Carlé, Jon Eggert; Helgesen, Martin; Bundgaard, Eva; Norrman, Kion; Andreasen, Jens Wenzel; Jørgensen, Mikkel

Total number of authors:

11

Published in:

A C S Nano

Link to article, DOI:

$10.1021 / \mathrm{nn} 200933 \mathrm{r}$

Publication date:

2011

Document Version

Publisher's PDF, also known as Version of record

Link back to DTU Orbit

Citation (APA):

Andersen, T. R., Larsen-Olsen, T. T., Andreasen, B., Böttiger, A. P. L., Carlé, J. E., Helgesen, M., Bundgaard, E., Norrman, K., Andreasen, J. W., Jørgensen, M., \& Krebs, F. C. (2011). Aqueous Processing of Low-BandGap Polymer Solar Cells Using Roll-to-Roll Methods. A C S Nano, 5(5), 4188-4196.

https://doi.org/10.1021/nn200933r

\section{General rights}

Copyright and moral rights for the publications made accessible in the public portal are retained by the authors and/or other copyright owners and it is a condition of accessing publications that users recognise and abide by the legal requirements associated with these rights.

- Users may download and print one copy of any publication from the public portal for the purpose of private study or research.

- You may not further distribute the material or use it for any profit-making activity or commercial gain

- You may freely distribute the URL identifying the publication in the public portal 


\title{
Aqueous Processing of Low-Band-Gap Polymer Solar Cells Using Roll-to-Roll Methods
}

\author{
Thomas R. Andersen, Thue T. Larsen-Olsen, Birgitta Andreasen, Arvid P. L. Böttiger, Jon E. Carlé, \\ Martin Helgesen, Eva Bundgaard, Kion Norrman, Jens W. Andreasen, Mikkel Jørgensen, and \\ Frederik C. Krebs*
}

Solar Energy Programme, Risø National Laboratory for Sustainable Energy, Technical University of Denmark, Frederiksborgvej 399, DK-4000 Roskilde, Denmark

A queous processing of polymer solar cells presents the ultimate challenge in terms of environmental friendliness and has only been reported in a few instances. The approaches to solubilization of the conjugated and active material in water fall in three categories: solubilization through (1) ionic side chains such as sulfonic acid, carboxylic acid, or ammonium, (2) nanoparticle dispersions of hydrophobic polymers in water, or (3) nonionic alcohol and glycol side chains. The latter approach is the most recent and most successful in terms of performance where PCEs of up to $0.7 \%$ have been reached on indium tin oxide (ITO) substrates with aqueous processing of the four subsequent layers in the solar cell stack (including the printed metal back electrode). ${ }^{1}$ The approach employing ionic side chains is perhaps conceptually the most appealing as it opens up for layer-by-layer assembly of the films or interface layers ${ }^{2}$ but has so far not been employed successfully for the active layer itself. The nanoparticle dispersion approach developed by Landfester et al. $^{3-7}$ is particularly appealing as it allows for control of the nanoparticle size and for processing using pure water as solvent for common hydrophobic conjugated polymers. In terms of development of the polymer and organic photovoltaic (OPV) technology, the latter point is of some significance since the large body of polymers available today has been developed for processing in organic solvents such as chlorobenzene, 1,2-dichlorobenzene, etc. One could envisage a complete redesign of the chemistry as described above ${ }^{1}$ (method 3) but it will require a complete rediscovery of the solventmaterial interaction and morphology relationships. While this may be necessary, in
ABSTRACT Aqueous nanoparticle dispersions of a series of three low-band-gap polymers poly[4,8-bis(2-ethylhexyloxy)benzo(1,2-b:4,5-b')dithiophene-alt-5,6-bis(octyloxy)-4,7-di(thiophen2-yl)(2,1,3-benzothiadiazole)-5,5'-diyl] (P1), poly[(4,4' -bis(2-ethylhexyl)dithieno[3,2-b:2, $3^{\prime}$-d] silole)-2,6-diyl-alt-(2,1,3-benzothiadiazole)-4,7-diyl] (P2), and poly[2,3-bis-(3-octyloxyphenyl)quinoxaline-5,8-diyl-alt-thiophene-2,5-diyl] (P3) were prepared using ultrasonic treatment of a chloroform solution of the polymer and [6,6]-phenyl- 661 $_{6}$-butyric acid methyl ester ([60]PCBM) mixed with an aqueous solution of sodium dodecylsulphate (SDS). The size of the nanoparticles was established using small-angle X-ray scattering (SAXS) of the aqueous dispersions and by both atomic force microscopy (AFM) and using both grazing incidence SAXS (GISAXS) and grazing incidence wide-angle X-ray scattering (GIWAXS) in the solid state as coated films. The aqueous dispersions were dialyzed to remove excess detergent and concentrated to a solid content of approximately $60 \mathrm{mg} \mathrm{mL}^{-1}$. The formation of films for solar cells using the aqueous dispersion required the addition of the nonionic detergent $\mathrm{FSO}-100$ at a concentration of $5 \mathrm{mg} \mathrm{mL}^{-1}$. This enabled slot-die coating of high quality films with a dry thickness of $126 \pm 19,500 \pm 25$, and $612 \pm 22 \mathrm{~nm} \mathrm{P1}, \mathrm{P2}$, and P3, respectively for polymer solar cells. Large area inverted polymer solar cells were thus prepared based on the aqueous inks. The power conversion efficiency (PCE) reached for each of the materials was $0.07,0.55$, and $0.15 \%$ for $\mathrm{P} 1, \mathrm{P} 2$, and $\mathrm{P} 3$, respectively. The devices were prepared using coating and printing of all layers including the metal back electrodes. All steps were carried out using roll-to-roll (R2R) slot-die and screen printing methods on flexible substrates. All five layers were processed using environmentally friendly methods and solvents. Two of the layers were processed entirely from water (the electron transport layer and the active layer).

KEYWORDS: roll-to-roll coating polymer solar cells · organic solar cells · slot-die coating $\cdot$ aqueous inks $\cdot$ nanoparticle dispersions

the end it is of interest to simply adapt the large body of materials at hand to an aqueous process. It is also of critical importance to replace the organic solvents if one has the ambition to manufacture polymer solar cells on a gigawatt scale.

There are several concerns associated with the use of chlorinated and aromatic solvents on a very large scale. Concern for the people working at the manufacturing machine is crucial both in terms of toxicity and, in the case of aromatic solvents, @2011 American Chemical Society 


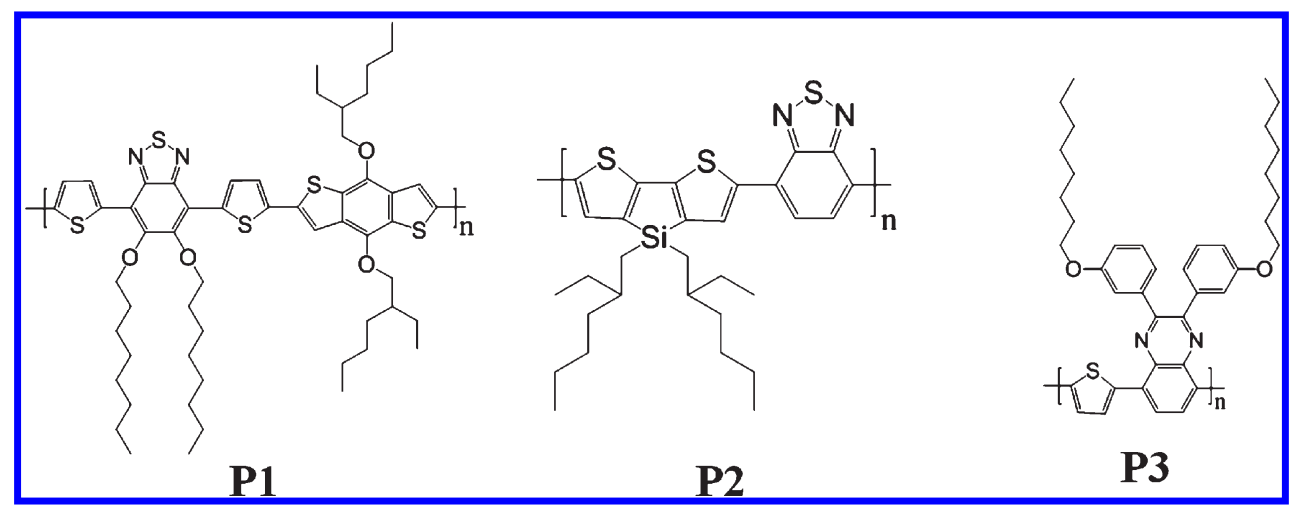

Figure 1. The structure for the three polymers used, P1, P2, and P3 (see text for the systematic names).

flammability. In the case of the chlorinated solvents the environmental concern is large, and it is unlikely that large scale manufacturing using such solvents is possible in a European setting. As an example, the current state of the art based on ProcessOne ${ }^{8}$ would involve approximately 16 million liters of chlorobenzene for the production of $1 \mathrm{GW}_{\mathrm{p}}$ of polymer solar cell. An additional concern is the cumulative energy needed for raw materials production, where a poor choice of processing method and processing materials can severely affect the energy payback time (EPBT) of the solar cell. Life cycle analysis has confirmed that water is the solvent that is most beneficial to use, requiring only a small electrical energy input for production. ${ }^{9}$ The cumulative thermal energy in materials production of chlorobenzene alone, as given in the example above, would be $880 \mathrm{TJ}$, adding 10 days to the EPBT. In contrast the use of water as the solvent would require only $17 \mathrm{TJ}$, adding only $4 \mathrm{~h}$ to the EPBT.

In terms of active materials the most successful approach so far has been the use of low-band-gap materials based on the donor-acceptor approach as shown in Figure 1. The UV-vis spectra of the three polymers P1, P2, and P3 were recorded, and the optical band gaps were determined to be 1.8, 1.5, and $1.8 \mathrm{eV}$, respectively (Figure 2 ).

In this work we prepared aqueous nanoparticle dispersions of the known low-band-gap polymers poly[4,8-bis(2-ethylhexyloxy)benzo(1,2-b:4,5-b')dithiophene-alt-5,6-bis(octyloxy)-4,7-di(thiophen-2-yl)(2,1,3benzothiadiazole)-5,5'-diyl] (P1), ${ }^{10}$ poly[(4,4'-bis(2-ethylhexyl)-dithieno[3,2-b:2', $3^{\prime}$-d]silole)-2,6-diyl-alt-(2,1, 3-benzothiadiazole)-4,7-diyl] (P2), ${ }^{11}$ and poly[2,3-bis(3-octyloxyphenyl)-quinoxaline-5,8-diyl-alt-thiophene-2, 5-diyl] (P3) ${ }^{12}$ (Figure 1) in mixtures with [60]PCBM. We developed an aqueous R2R manufacturing process for flexible polymer solar cells through careful ink formulation and processing.

\section{RESULTS AND DISCUSSION}

Overview. The polymer solar cell has grown from a laboratory experiment to an emerging technology

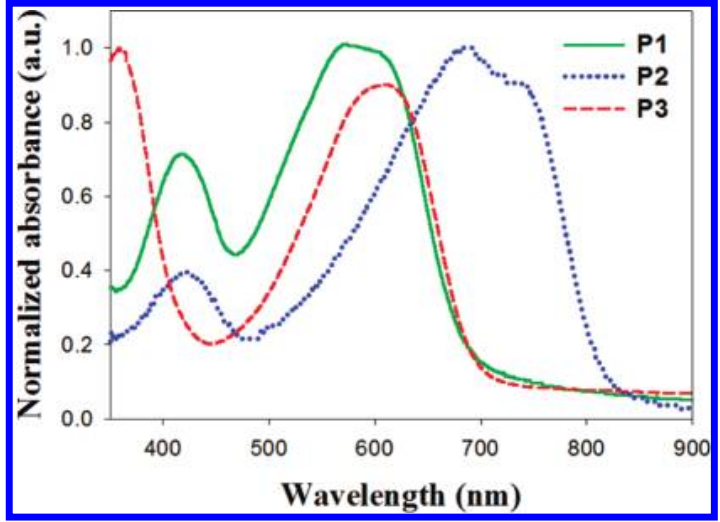

Figure 2. The UV-vis spectra of P1, P2, and P3. The optical band gap was determined to $1.8,1.5$, and $1.8 \mathrm{eV}$ for P1, P2, and $\mathrm{P} 3$, respectively.

with great potential to significantly contribute to future energy production. Currently, polymer solar cells can be prepared using industrial roll-to-roll methods ${ }^{8}$ and are sufficiently stable for demonstration products. They have for instance been employed as a low cost lighting solution for developing countries. ${ }^{13}$ While upscaling has been described successfully their current potential should be viewed critically ${ }^{14,15}$ and compared to existing thin film solar cell technologies such as CdTe and amorphous silicon. The polymer solar cell is currently the poorest performing PV technology (in existence) in terms of power conversion efficiency, while it has distinct advantages of high speed production, adaptability, and an abundance of raw materials. Recent work on the life cycle analysis from several groups ${ }^{9}$ have highlighted the potential of the technology and in one case, where the source of data was fully public, revealed EPBTs in the range of $1.35-2.02$ years. ${ }^{9}$ As outlined in the introduction there is an urgent need for processes and processing materials that lower the embedded energy and the process energy, as this is a necessary method for lowering the EPBT. This should of course go in hand with an increase in efficiency. In this work where we aim at replacing the organic solvent for processing of the active area with water there is a direct gain at the site of manufacture but it should be emphasized that solvents and large amounts of 
detergent are required for the manufacture of the nanoparticle dispersions. It is assumed that those can be recycled to fully benefit from the aqueous processing of hydrophobic materials that has already been developed. If this is not the case then there might not be any gain in the cumulative energy for raw materials production but there will still be a large gain in terms of human safety and lower emission of chlorinated or aromatic solvent into the environment because the preparation of the nanoparticle dispersions inherently allows for containment and reuse of solvents. A detailed life cycle analysis of the inks is thus warranted and until this has been carried out a complete comparison is not possible. At this point however the benefits of an aqueous ink are large enough to justify research in this direction.

Formation of Nanoparticle Dispersions. The generic method developed by Landfester et al. in a series of original research papers during the period from 1999 to 2004 was followed and found to be directly applicable with minor modifications. ${ }^{3-7}$ A significantly larger amount of SDS was found to be needed than reported previously for a given nanoparticle size. The correlation between the size of the nanoparticles and the amounts of solvent, water, and SDS seem to be depending on the properties of the individual polymers. We found that a $100 \mathrm{mM}$ SDS solution and a solid content in the organic phase of $\sim 40 \mathrm{mg} \mathrm{mL}^{-1}$ reproducibly gave nanoparticles with a size below $150 \mathrm{~nm}$ as established with SAXS measurements. We also found that the nanoparticles were conserved in the coated films (vide supra). The observed discrepancy in particle size as a function of SDS content could also be linked to the

TABLE 1. The Average Particle Diameter in P1, P2, and P3 As Determined by SAXS and AFM. The Standard Deviation Is Given in the Brackets

\begin{tabular}{ccll} 
polymer & SAXS (dispersions) & AFM (films) & GISAXS (films) \\
\hline P1 & $130(38) \mathrm{nm}$ & $a$ & $a$ \\
P2 & $32(10) \mathrm{nm}$ & $69(47) \mathrm{nm}$ & $32(22) \mathrm{nm}$ \\
P3 & $87(21) \mathrm{nm}$ & $120(82) \mathrm{nm}$ & $107(72) \mathrm{nm}$ \\
\hline
\end{tabular}

${ }^{a}$ Not possible to establish due to aggregation in the sample. method of particle size determination where light scattering was employed previously. The reported method for the removal of the excess detergent comprises dialysis and centrifugal dialysis. These methods however allow for the preparation of only small quantities of ink. In our case large volumes (>100 mL) of inks with a high solid content was needed, and we initially attempted using a large basket centrifuge allowing for the continuous addition of water but finally settled on a Millipore filter system with a processing volume of $500 \mathrm{~mL}$. Using this method, ink volumes of $100 \mathrm{~mL}$ with a solid content of $60 \mathrm{mg} \mathrm{mL}^{-1}$ could be prepared in a few hours. The inks were diluted 625 times corresponding to a final SDS concentration in the ink of $0.16 \mathrm{mM}$.

Particle Size and Crystalline Order. SAXS was employed on both the aqueous dispersions and on the solid films to determine particle sizes. AFM images of the films were analyzed to determine particle size distributions and gave similar results.

GIWAXS data showed poorly developed crystalline order of polymers $\mathbf{P} \mathbf{2}$ and $\mathbf{P} \mathbf{3}$, with only weak first order reflections corresponding to lamellar spacings of 18.2 and $24.0 \AA$, respectively, and a broad peak at $\sim 1.34 \AA^{-1}$ that we ascribe to packing of disordered side chains. P1 showed very weak scattering, with no features that may be attributed to crystalline order of the polymer (the wide peak at high $q$ values is the background signal from the glass substrate). All three films show a weak peak at $\sim 0.69 \AA^{-1}$ that we ascribe to nanocrystalline [60]PCBM (Table 1 and Figures 3 and 4).

Inks and Roll-to-Roll Coating. The spin coating of thin films was possible, whereas large area films with the thickness/coverage required for making functional OPV devices was not possible. It was further found impossible to successfully coat these inks even with very fast web speeds and fast drying on a heated roller and a short distance $(18 \mathrm{~cm})$ between the coating head and the oven. Web speeds as high as $8 \mathrm{~m} \mathrm{~min}^{-1}$ were employed with a roller temperature of $80{ }^{\circ} \mathrm{C}$. By heating the foil just after coating, quick drying was possible (within seconds), but significant dewetting was still observed (see Supporting Information).

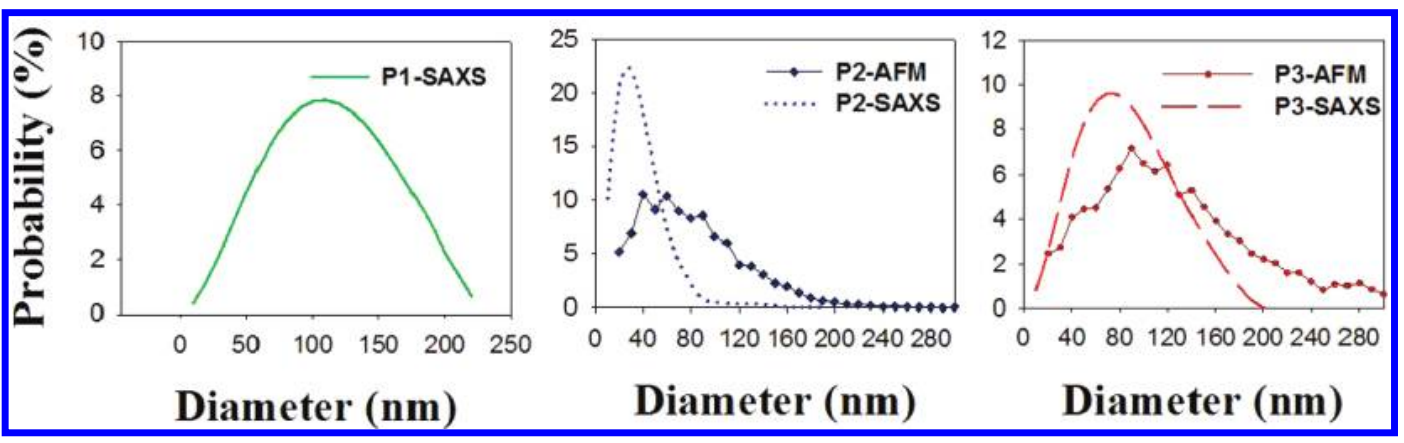

Figure 3. Size distributions of the particles P1 (left), P2 (middle), P3 (right) measured by AFM and SAXS. The SAXS measurements were performed with the particles in a water suspension, and the AFM was measured from spin-coated films. The distribution of $\mathrm{P} 1$ could not be determined by AFM due to aggregation of the particles. 
Careful inspection of the wetting behavior revealed that the ink initially wets the surface and then dewets leaving a thin film (possibly comprising a single layer of nanoparticles). We ascribe this to the initial wetting and drying followed by lowering of the surface energy of the first layer and subsequent dewetting of the higher surface tension solution.

This phenomenon is quite well-known in the area of coating technology and is in essence a result of poisoning the otherwise wetable surface by the surface active properties of the ink itself. To solve this problem, the addition of a nonionic fluorosurfactant (FSO-100) was found to be necessary. The amount added was critical, and with too little material dewetting was still observed,

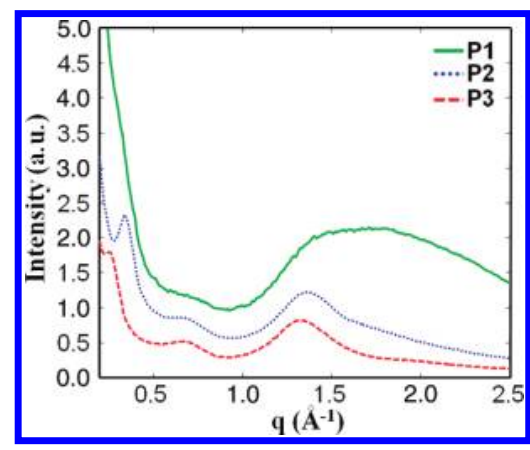

Figure 4. GIWAXS patterns of the three polymers, spincoated on glass. No texture was observed, and the 2D patterns were thus azimuthally averaged as a function of $q$. The patterns are scaled for clarity. whereas too much led to films with extremely poor adhesion. A concentration of $5 \mathrm{mg} \mathrm{mL}^{-1}$ was found to be the best compromise between coatability and adhesion. Films prepared in this manner passed the tape test. ${ }^{16}$ The age of the meniscus was found to be of critical importance for efficient wetting and good adhesion of the dried film. This phenomenon is wellknown in the area of coating technology, where shear induced in the ink as a result of the coating process itself leads to depletion of surfactant at the surface of the ink. In the case of water based inks this implies that the surface tension of the ink in the region of coating increases to a level where dewetting occurs. In such cases the speed of the coating process must be decreased to a level where the surfactant has time to diffuse to the surface and maintain the lower surface tension. Web speeds of $1 \mathrm{~m} \mathrm{~min} \mathrm{me}^{-1}$ were found to present the best conditions even though web speeds as high as $1.6 \mathrm{~m} \mathrm{~min}^{-1}$ could also be employed. A web speed of $0.6 \mathrm{~m} \mathrm{~min}^{-1}$ was used in all experiments to fabricate the devices presented in this work. Examples of dewetting during coating can be seen in the Supporting Information, and correct wettings are shown in Figure 5. The thickness of the dry active layers of $\mathbf{P 1}, \mathbf{P} \mathbf{2}$, and $\mathbf{P} \mathbf{3}$ were measured by AFM profilometry and were found to be $126 \pm 19,500 \pm 25$, and $612 \pm 22 \mathrm{~nm}$, respectively.

The devices were completed by slot-die coating poly(3,4-ethylenedioxythiophene) poly(styrenesulfonate) (PEDOT:PSS) on top of the active layer and interestingly

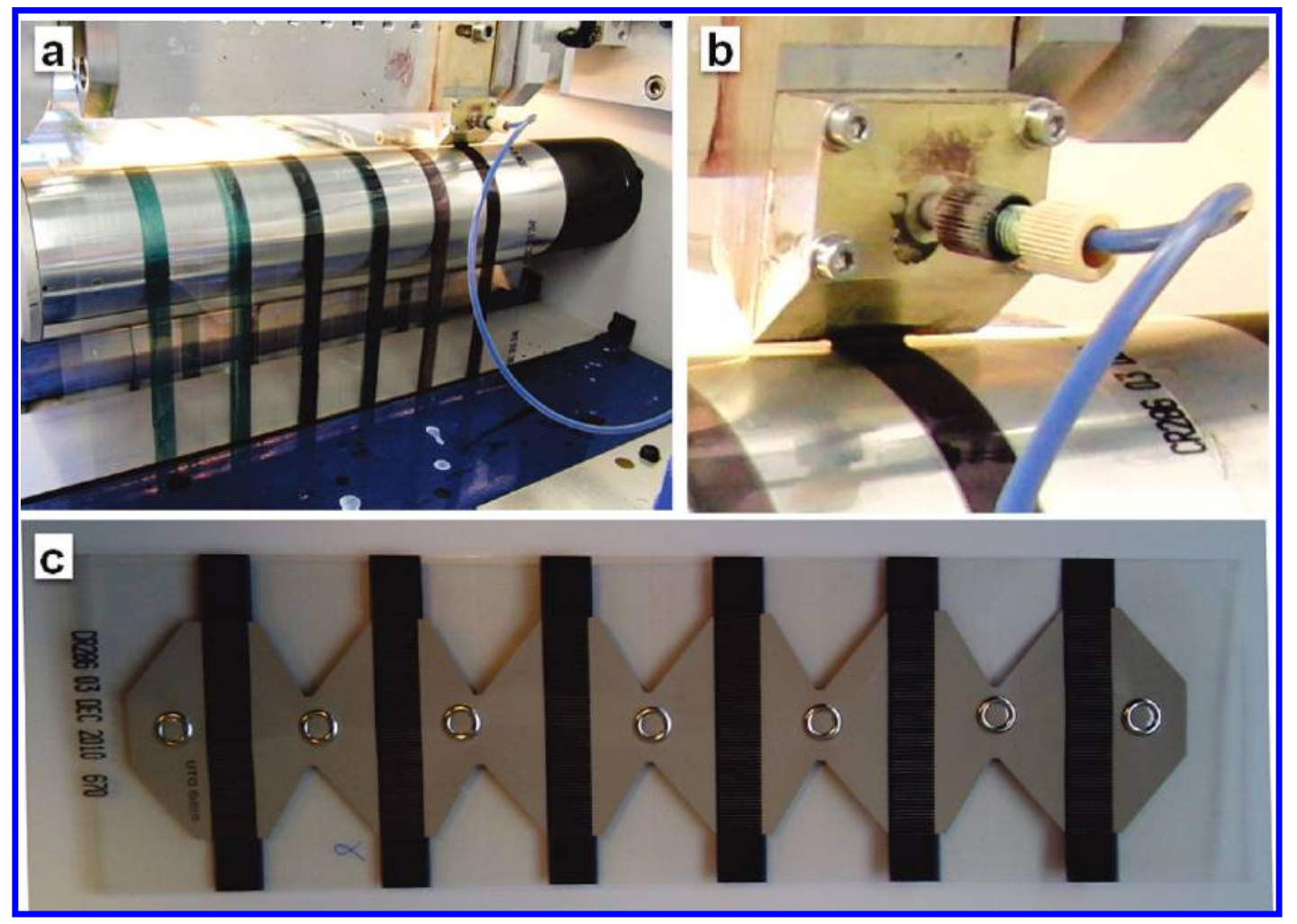

Figure 5. (a) Slot-die coating of the active layer using the aqueous nanoparticle dispersions and (b) an enlargement of the coating head, coating bead and wet film, and (c) showing a complete device with six individual solar cells. 


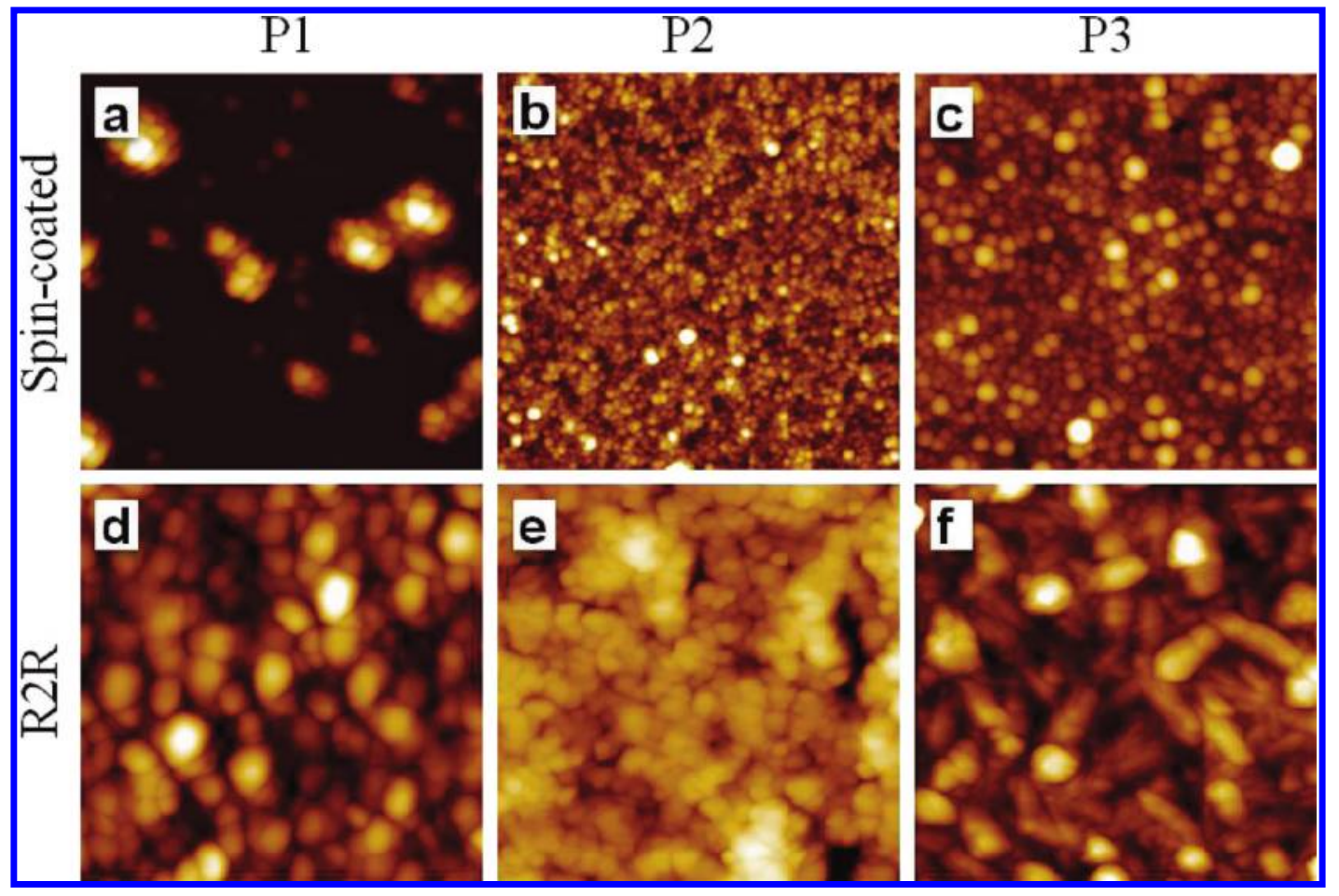

Figure 6. AFM topography images of spin-coated $(a-c)$ and $R 2 R(d-f)$ prepared samples of $P 1, P 2$, and $P 3$. All the images were taken at $5 \times 5 \mu \mathrm{m}^{2}$.

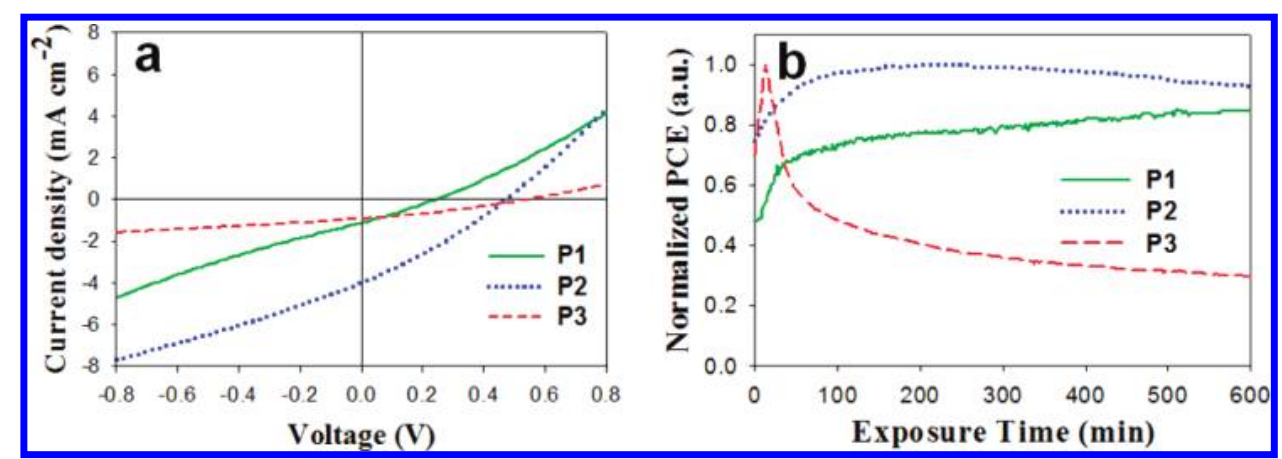

Figure 7. (a) $I V$-curves for the devices based on the three different polymers, at peak performance (AM1.5G, $1000 \mathrm{~W} \mathrm{~m}^{-2}, 85 \pm$ $5{ }^{\circ} \mathrm{C}$ ). (b) The development of the solar cell PCE during the initial $10 \mathrm{~h}$ of the exposure to 1 sun is shown for the three different polymers. Values are normalized to the corresponding peak value for each polymer (see Table 2).

no prewetting of the active layer with isopropyl alcohol was needed. We ascribe this to a fortuitous interaction between the fluorosurfactants in the PEDOT:PSS formulation and in the coated active layer. The devices were completed by screen printing a silver ink onto the PEDOT:PSS electrode. The devices were finally encapsulated using a simple barrier foil as described earlier and tested using an automated roll-to-roll IV-tester., 84,15

Morphology. The morphology differences between spin-coated and R2R prepared samples and between the different sample materials can clearly be observed in the AFM images in Figure 6. On the spin-coated samples the individual nanoparticle shapes can be observed (with exception of P1, which looks like agglomerates made up of smaller particles). In the R2R samples the nanoparticles can no longer be clearly distinguished; instead it looks like the nanoparticles have merged in places. The different morphologies observed across the R2R samples could be caused by the "harsh" process conditions, where annealing at high temperatures is involved, and due to the different thermal properties of the polymers.

When the R2R coated samples in Figure 6 panels $d$, e, and $f$ are compared, it looks like the particles are increasingly merged $(d<f<e)$. This could be because these samples were prepared at slightly different conditions with the annealing time increasing $(d<f<e)$. Each roll-to-roll experiment (a roll of foil) comprises six coated stripes as described earlier. ${ }^{15}$ The first coated stripe will thus pass the oven a total of eight times, whereas that last coated stripe will pass the oven a total of three times (including the two passages when 
coating PEDOT:PSS and printing the silver back electrode).

Device Performance. The freshly prepared devices were put under a calibrated solar simulator (AM1.5G, $1000 \mathrm{~W} \mathrm{~m}^{-2}$ ) and $I V$-scans were recorded every $1 \mathrm{~min}$, for up to $36 \mathrm{~h}$ (according to the ISOS-L-1 procedure ${ }^{26}$ using a temperature of $85 \pm 5^{\circ} \mathrm{C}$ ). For all devices an initial steady increase in PCE during exposure to sunlight was generally observed.

However the optimum period of light exposure was significantly different for the three photoactive polymers, as can be seen in Figure 7. The PCE increase was caused by improvement of both the short circuit current and open circuit voltage, while the fill-factor was relatively constant. This behavior is not unique for these cells prepared from water-dispersed nanoparticles, but is readily observed for other polymer solar cells, having the same layer structure but an active layer processed from organic solvents such as chlorobenzene. ${ }^{15}$ It is ascribed to a combination of effects such as photodoping of the zinc oxide layer by UV-light, accompanied by beneficial morphological changes in the active layer due to the relatively high temperature $\left(85 \pm 5^{\circ} \mathrm{C}\right) . .^{14}$

The devices prepared from the aqueous dispersions show poorer performance compared to earlier reported efficiencies for devices based on P1, P2, and P3, prepared using chlorobenzene as solvent (Figure 7). ${ }^{10-12}$ The source of this most likely shunts across the active layer. Because of the particle nature of the active layers (Figure 6), the film will be somewhat porous and thus susceptible to shunting by the subsequent processing of PEDOT:PSS. It is thus likely that the amount of shunts should be dependent on the layer thickness relative to the particle diameters. When the obtained PCEs for the different polymers are

TABLE 2. The Photovoltaic Properties Obtained for the Devices When Processed from Water ${ }^{a}$

\begin{tabular}{ccccc} 
polymer & $\boldsymbol{V}_{\text {oc }}(\mathrm{V})$ & $J_{\text {sc }}\left(\mathrm{mA} \mathrm{cm}^{-2}\right)$ & FF (\%) & PCE (\%) \\
\hline P1 & 0.24 & 1.10 & 27.5 & 0.07 \\
P2 & 0.47 & 3.99 & 29.3 & 0.55 \\
P3 & 0.54 & 0.92 & 30.8 & 0.15 \\
\hline
\end{tabular}

${ }^{a}$ The device geometry was PET/IT0/Zn0/polymer-[60]PCBM/PEDOT:PSS/Ag(printed), and the active area of the devices was $4 \mathrm{~cm}^{2}$. The testing conditions were AM1.5G, $1000 \mathrm{~W} \mathrm{~m}^{-2}, 85 \pm 5^{\circ} \mathrm{C}$. compared, it is observed that thicker layers and smaller particle size seem to give a higher performance. Apart from these suspected microscopic shunts, there are some larger shunts for some devices due to incomplete coverage evident from optical inspection of the film and even more so from the light beam induced current (LBIC) scan shown in Figure 8 where (blue) dots within the (red/green) active area reveal such shunts. Furthermore, effects from the significant amount of fluorosurfactant present in the ink along with the residual SDS bound to the surface of the nanoparticles have not been determined. This does however show that it is possible to prepare devices from water with a nonnegligible performance, and worth noting that a large part of the relatively low performance of these devices prepared from water could be due to coating technicalities that are bound to become less pronounced as further experience is gained.

Directions for Future Work. The possibility of achieving aqueous processing and operator safety and avoiding the emission of environmentally harmful solvents to the environment was demonstrated, and while this is a great step forward it was achieved at the expense of using a fluorinated surfactant. There is a well-documented concern over release of fluorinated surfactants to the environment where extremely harmful effects have been documented. ${ }^{17}$ In our case the surfactant is not released directly to the environment but will follow the solar cell until the end of its life cycle, where it should be properly disposed. The identification of existing environmentally friendly surface active materials or the development of new ones for coating should be researched actively to avoid the use of fluorinated detergents while maintaining the advantages of aqueous processing of OPV.

The relationship between the chemical disposition of the polymer materials and nanoparticle size in the final ink will have to be established along with the relationship between the size of the nanoparticles and the performance of the solar cell printed from them. Since this requires quite large quantities of conjugated polymer material, the type of materials that perform best should be identified followed by replacement of the fluorinated surfactant. Once the truly environmentally friendly ink with the best performance has been identified the ink can be finally optimized with respect to nanoparticle size, solid content, drying time, etc.

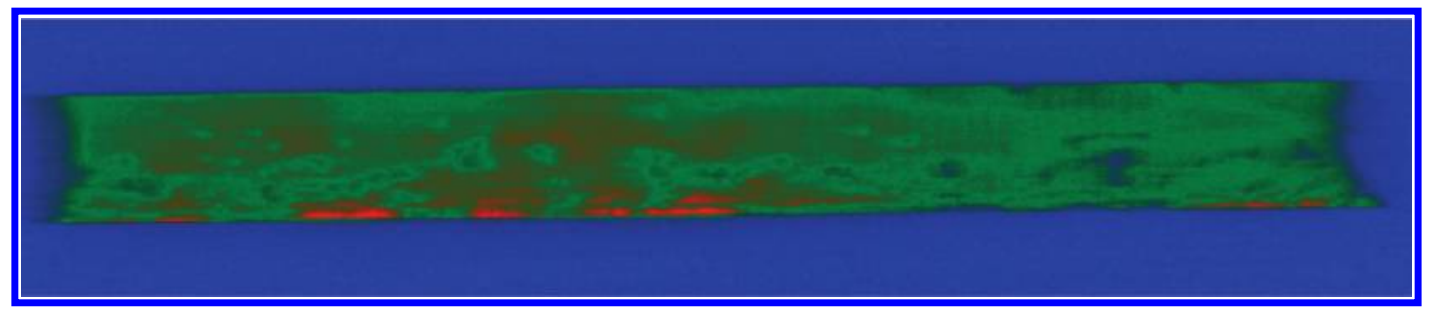

Figure 8. The LBIC image for a mapping of a P2 cell. The intensity scale is going from blue with no intensity over green to red with high intensity. 
In our case $\mathbf{P} \mathbf{2}$ proved to work best and further optimization using this class of materials should be pursued.

\section{CONCLUSIONS}

We have successfully prepared aqueous nanoparticle dispersions of three low-band-gap polymers and formulated inks for roll-to-roll processing into polymer solar cells on a flexible substrate which resulted in PCEs of $0.55,0.15$, and $0.07 \%$ for poly $\left[\left(4,4^{\prime}\right.\right.$-bis (2-ethylhexyl)dithieno[3,2-b:2', 3'-d]silole)-2,6-diyl-alt(2,1,3-benzothiadiazole)-4,7-diyl], poly[2,3-bis-(3-octyl oxyphenyl)-quinoxaline-5,8-diyl-alt-thiophene-2,5-diyl], and poly[4,8-bis(2-ethylhexyloxy)benzo(1,2-b:4,5-b') dithiophene-alt-5,6-bis(octyloxy)-4,7-di(thiophen-2-yl) (2,1,3-benzothiadiazole)-5,5'-diyl], respectively. We analyzed the nanoparticles in aqueous dispersion using SAXS and in solid film using GISAXS, GIWAXS, and AFM. The ink formulation and roll-to-roll processing was found to be challenging, however a reproducible method giving homogeneous films that adhered well to the surface of the zinc oxide based electron transport layer was obtained. The relatively poor device performance is ascribed to shunting and non-optimum morphology. Further work should be directed at improving coating condition and ink formulation as this has been successful in the case of organic solvent systems.

\section{METHODS}

Materials. The polymers were prepared as described in the literature. ${ }^{10-12}$ They had values for $M_{\mathrm{n}}, M_{\mathrm{w}}$, and polydispersities of, respectively, $11.0 \mathrm{kDa}, 28.7 \mathrm{kDa}$, and 2.6 for $\mathbf{P 1}, 6.0 \mathrm{kDa}, 10.9 \mathrm{kDa}$ and 1.8 for $\mathbf{P 2}$, and $21.0 \mathrm{kDa}, 89.0 \mathrm{kDa}$, and 4.2 for P3. [60]PCBM, SDS and chloroform were purchased in standard grade. An aqueous precursor solution for the zinc oxide was prepared as described in the literature. ${ }^{1}$ PEDOT:PSS was based on EL-P 5010 from Agfa that was diluted with isopropyl alcohol to a viscosity of $200 \mathrm{mPa} \cdot \mathrm{s}$. The printable silver back electrode was PV410 from Dupont.

Nanoparticle Preparation. The typical recipe for small scale production, the polymer material $(0.3 \mathrm{~g})$ was together with [60]PCBM $(0.3 \mathrm{~g})$ dissolved in chloroform $(15.5 \mathrm{~mL})$ and mixed with an aqueous $100 \mathrm{mM}$ SDS solution $(50 \mathrm{~mL})$ in a large beaker. The mixture was stirred vigorously for $1 \mathrm{~h}$ and then subjected to ultrasound (1 kW) for 5 min using an UIP 1000hd transducer from Hielscher ultrasound technology fitted with a booster head. The mixture was then stirred on a hot plate at $65^{\circ} \mathrm{C}$ for $3 \mathrm{~h}$ until all the chloroform had evaporated. For small scale preparations, the aqueous dispersion was then dialyzed in dialysis tubing against $2 \times 10 \mathrm{~L}$ pure water. In the final step the suspensions were concentrated to have a solid content of approximately $60 \mathrm{mg} \mathrm{mL}^{-1}$.

For large scale preparations, the aqueous dispersion was dialyzed using a Millipore system with a capacity of $500 \mathrm{~mL}$. The mixture was concentrated by dialysis from a volume of $500 \mathrm{~mL}$ to a volume of $100 \mathrm{~mL}$ with a forward pressure of 1.4 bar and a pressure gradient across the filter of 0.7 bar. Pure water $(400 \mathrm{~mL})$ was then added and the procedure was repeated 4 times corresponding to a dilution of the solution by a factor of 625 . In the final step the suspensions were concentrated to have a solid content of $60 \mathrm{mg} \mathrm{mL}^{-1}$.

$X$-ray Scattering. The SAXS and grazing incidence SAXS (GISAXS) experiments were performed at a laboratory setup using a rotating Cu-anode operating at $46 \mathrm{kV}$ and $46 \mathrm{~mA}$ as X-ray source. The SAXS instrument was configured for a fully evacuated sample to detector distance of $4579 \mathrm{~mm}$ covering a $q$-range of $2.5 \times 10^{-3}<q<0.12 \AA^{-1}$, where the length of the scattering vector $q=4 \pi \sin (\theta) / \lambda$, with $\theta$ equal to half the scattering angle, and $\lambda$ being the $\mathrm{X}$-ray wavelength for $\mathrm{Cu} \mathrm{K \alpha}$ (1.5418 ̊̊). The X-rays are monochromated and collimated by two-dimensional multilayer optics and detected by a $2 \mathrm{D}$ "Gabriel"-type gas-proportional delay line detector. ${ }^{18}$ The nanoparticle dispersions were measured in $1 \mathrm{~mm}$ borosilicate capillaries, sealed with epoxy glue for the SAXS experiments, and GISAXS of films spin-coated on glass were measured by orienting the substrate at an X-ray incidence angle of $0.5^{\circ}$. The 2D scattering images of the randomly oriented particles in dispersion were reduced to $1 \mathrm{D}$ cross sections by azimuthal averaging, whereas the GISAXS scattering were reduced to $1 \mathrm{D}$ curves by taking projections through the Yoneda peak ${ }^{18}$ at constant $q_{z}$. The reduced 1D data were analyzed by using the Bayesian inverse Fourier transform (BIFT). ${ }^{19}$

GIWAXS of spin-coated films on glass were acquired by orienting the substrate surface just below the critical angle for total reflection with respect to the incoming X-ray beam $\left(0.18^{\circ}\right)$, maximizing scattering from the deposited film with respect to scattering from the substrate. In the wide scattering angle range $\left(>5^{\circ}\right)$, the X-ray scattering is sensitive to crystalline structure. For the experiment we used a camera comprising an evacuated sample chamber with an X-ray photosensitive image plate as detector and a rotating $\mathrm{Cu}$ anode operating at $50 \mathrm{kV} / 200 \mathrm{~mA}$ as $\mathrm{X}$-ray source, focused and monochromatized $(\mathrm{Cu} \mathrm{K \alpha}, \lambda=1.5418 \AA$ ) by a $1 \mathrm{D}$ multilayer. ${ }^{19}$ The samples were mounted $120 \mathrm{~mm}$ from the detector. The GIWAXS data were analyzed by reducing the acquired $2 \mathrm{D}$ data by azimuthal averaging of intensity as a function of scattering vector length, $q$, to determine the characteristic $d$-spacings of the polymers, using the software SimDiffraction. ${ }^{20}$

Atomic Force Microscopy. AFM imaging was performed on an N8 NEOS (Bruker Nano GmbH, Herzogenrath, Germany) operating in an intermittent contact mode using PPP-NCLR cantilevers (NANOSENSORS, Neuchatel, Switzerland). Images were recorded at a scan speed of 0.8 lines $\mathrm{min}^{-1}$. The images were analyzed using the image processing software package SPIP 5.1.5 (Image Metrology A/S, Hørsholm, Denmark).

The samples were first delaminated by ripping the plastic laminate off in a swift motion and thereafter placed on a glass slide using double sided tape.

It is well-known that AFM can at times overestimate particle sizes in the lateral plane and therefore the height $z$ is often used as a measure for the diameter of spherical particles. ${ }^{21-23} \mathrm{How}-$ ever, since the particles in the samples at hand are closely packed the height measurements of individual particles would be too time-consuming and inaccurate. ${ }^{24}$ Therefore the best estimate to determine the particle size was to employ the Particle \& Pore Analysis module included in the SPIP 5.1.5 software. The size was analyzed on at least two different positions of the sample analyzing a minimum of 2000 particles on each sample.

The thicknesses of the dry films were measured by AFM profilometry, see Figure 9. The thickness was measured at a minimum of three different positions on each film, with each position consisting of at least three individual measurements.

Light Beam Induced Current (LBIC) Mapping. The LBIC experiments were carried out using a custom-made setup with $410 \mathrm{~nm}$ laser diode ( $5 \mathrm{~mW}$ output power, $100 \mu \mathrm{m}$ spot size $\left(\approx 65 \mathrm{~W} / \mathrm{cm}^{-2}\right)$, ThorLabs) mounted on a computer controlled $X Y$-stage and focused to a spot size of $<100 \mu \mathrm{m}$. The short circuit current from the device under study was measured using a computer 


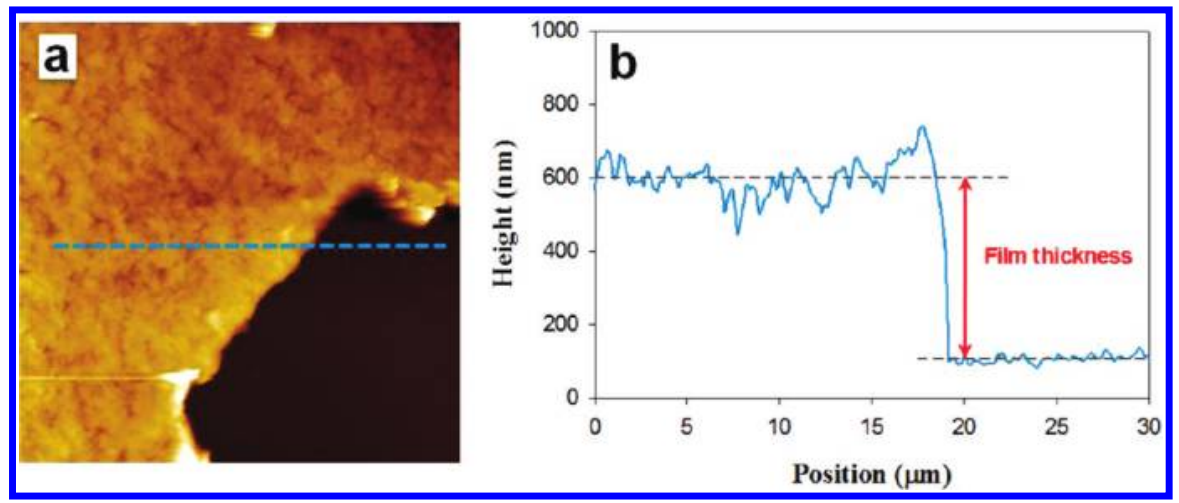

Figure 9. (a) $30 \times 30 \mu \mathrm{m}^{2} \mathrm{AFM}$ topography image indicating where the thickness was measured. (b) line profile extracted from the AFM image (dashed line).

controlled source measure unit (Keithley 2400), and mapped by raster scanning across the device. Further details are available elsewhere. ${ }^{25}$

Ink Formulation. The nonionic fluorosurfactant (FSO-100) was added to the dialyzed aqueous suspension of the polymer/[60]PCBM nanoparticles. The concentration of fluorosurfactant was $5 \mathrm{mg} \mathrm{mL}^{-1}$ and the polymer/[60]PCBM concentration was $60 \mathrm{mg} \mathrm{mL}^{-1}$. This solution was employed directly for slot-die coating

Roll-to-Roll Coating. A PET substrate with an ITO pattern was prepared and cleaned as described earlier. ${ }^{13-15}$ The zinc oxide precursor solution was prepared as described earlier ${ }^{1}$ and comprised $\mathrm{Zn}(\mathrm{OAc})_{2} \cdot 2 \mathrm{H}_{2} \mathrm{O}\left(100 \mathrm{mg} \mathrm{mL}^{-1}\right), \mathrm{Al}(\mathrm{OH})(\mathrm{OAc})_{2}$ $\left(2 \mathrm{mg} \mathrm{mL}^{-1}\right)$, and FSO-100 $\left(2 \mathrm{mg} \mathrm{mL}^{-1}\right)$ in water. This solution was microfiltered immediately prior to use $(0.45 \mu \mathrm{m})$ and then slot-die coated at a speed of $2 \mathrm{~m} \mathrm{~min}^{-1}$ with a wet thickness of $4.9 \mu \mathrm{m}$. After the initial drying of the precursor film it was converted into an insoluble film by passage through an oven at a temperature of $140{ }^{\circ} \mathrm{C}$ with a speed of $0.2 \mathrm{~m} \mathrm{~min}^{-1}$ (oven length $=4 \mathrm{~m}$ ). This gave an insoluble doped zinc oxide film with a thickness of $25 \pm 5 \mathrm{~nm}$. The aqueous polymer/[60]PCBM nanoparticle dispersion was then slot-die coated at a speed of $1 \mathrm{~m} \mathrm{~min}^{-1}$ with a wet thickness of $30.4,17.6$, and $20.8 \mu \mathrm{m}$ for P1, $\mathbf{P 2}$, and $\mathbf{P 3}$, respectively. The coating speed and the time between application of the wet film and the drying were critical for successful formation of a homogeneous film without dewetting. The slot-die coating head had a temperature of $60^{\circ} \mathrm{C}$, the coating roller had a temperature of $80^{\circ} \mathrm{C}$, and the temperature of the foil was kept at $80^{\circ} \mathrm{C}$ until it reached the oven at $140{ }^{\circ} \mathrm{C}$. The distance from the point of coating to the oven entry was $18 \mathrm{~cm}$. PEDOT:PSS was then applied by slot-die coating at a speed of $0.2 \mathrm{~m} \mathrm{~min}^{-1}$ and dried at $140^{\circ} \mathrm{C}$ (oven length $=2 \mathrm{~m}$ ). It was found unnecessary to wet the film surface prior to coating the PEDOT:PSS and this might be due to the beneficial interaction between the fluorosurfactants in the active layer film and in the PEDOT:PSS. Finally the device was completed by roll-to-roll screen printing a silver grid electrode and drying at $140^{\circ} \mathrm{C}$. The devices were encapsulated using roll-to-roll lamination of a simple food packaging barrier with a pressure sensitive adhesive onto both sides of the foil. ${ }^{13-15}$

IV-Characterization. In each coated stripe that represents one set of experiments a total of 150 solar cells were prepared (900 cells for each roll). The devices were light soaked with continuous sweeping of the $I V$-curve until a constant performance was reached. Typically the performance dropped rapidly during the first 10 min of light soaking followed by a slow improvement in performance over $4-6 \mathrm{~h}$ where a stable level of performance was reached. The data reported is for the stable regime. The devices were initially tested using a roll-to-roll tester and the functional devices were the recovered for further testing using a calibrated solar simulator (AM1.5G, $1000 \mathrm{~W} \mathrm{~m}^{-2}, 85 \pm 5^{\circ} \mathrm{C}$ ). The prolonged testing was made according to the ISOS-L-1 procedure. ${ }^{26}$

Acknowledgment. This work was supported by the Danish National Research Foundation. We gratefully acknowledge the assistance of Steen Hansen with modifying the BIFT algorithm for use with polydisperse systems and Lasse Gorm Jensen for creating graphical illustrations.

Supporting Information Available: Details of the GISAXS analysis of solid films, with data and the description of the data reduction procedure; details of dewetting during coating. This material is available free of charge via the Internet at http:// pubs.acs.org.

\section{REFERENCES AND NOTES}

1. Søndergaard, R.; Helgesen, M.; Jørgensen, M.; Krebs, F. C. Fabrication of Polymer Solar Cells Using Aqueous Processing for All Layers Including the Metal Back Electrode. Adv. Eng. Mater. 2011, 1, 68-71.

2. Rider, D. A.; Worfolk, B. J.; Harris, K. D.; Lalany, A.; Shahbazi, K.; Fleischauer, M. D.; Brett, M. J.; Buriak, J. M. Stable Inverted Polymer/Fullerene Solar Cells Using a Cationic Polythiophene Modified PEDOT:PSS Cathodic Interface. Adv. Funct. Mater. 2010, 20, 2404-2415.

3. Landfester, K. The Generation of Nanoparticles in Miniemulsions. Adv. Mater. 2001, 13, 765-768.

4. Kietzke, T.; Neher, D.; Landfester, K.; Montenegro, R.; Güntner, R.; Scherf, U. Novel Approaches to Polymer Blends Based on Polymer Nanoparticles. Nat. Mater. 2003, 2, 408-412.

5. Piok, T.; Gamerith, S.; Gadermaier, C.; Plank, H.; Wenzl, F. P.; Patil, S.; Montenegro, R.; Kietzke, T.; Neher, D.; Scherf, U.; et al. Organic Light-Emitting Devices Prepared from Semiconducting Nanospheres. Adv. Mater. 2003, 15, 800-804.

6. Kietzke, T.; Neher, D.; Kumke, M.; Montenegro, R.; Landfester, K.; Scherf, U. A Nanoparticle Approach to Control the Phase Separation in Polyfluorene Photovoltaic Devices. Macromolecules 2004, 37, 4882-4890.

7. Antonietti, M.; Landfester, K. Polyreactions in Miniemulsions. Prog. Polym. Sci. 2002, 27, 689-757.

8. Krebs, F. C.; Gevorgyan, S. A.; Alstrup, J. A Roll-to-Roll Process to Flexible Polymer Solar Cells: Model Studies, Manufacture, and Operational Stability Studies. J. Mater. Chem. 2009, 19, 5442-5442.

9. Espinosa, N.; García-Valverde, R.; Urbina, A.; Krebs, F. C. A Life Cycle Analysis of Polymer Solar Cell Modules Prepared Using Roll-to-Roll Methods Under Ambient Conditions. Sol. Energy Mater. Sol. Cells 2011, 95, 1293-1302.

10. Bundgaard, E.; Hagemann, O.; Jørgensen, M.; Krebs, F. C. Low-Band-Gap Polymers for Roll-to-Roll Coated Organic Photovoltaics Design, Synthesis and Characterization. Green 2011, 1, 55-64.

11. Hou, J.; Chen, H. Y.; Zhang, S.; Li, G.; Yang, Y. Synthesis, Characterization, and Photovoltaic Properties of a Low Band Gap Polymer Based on Silole-Containing Polythiophenes and 2,1,3-Benzothiadiazole. J. Am. Chem. Soc. 2008, 130, 16144-16145.

12. Wang, E.; Hou, L.; Wang, Z.; Hellström, S.; Zhang, F.; Inganäs, O.; Andersson, M. R. An Easily Synthesized Blue 
Polymer for High-Performance Polymer Solar Cells. Adv. Mater. 2010, 22, 5240-5244.

13. Krebs, F. C.; Nielsen, T. D.; Fyenbo, J.; Wadstrøm, M.; Pedersen, M. S. Manufacture, Integration and Demonstration of Polymer Solar Cells in a Lamp for the "Lighting Africa" Initiative. Energy Environ. Sci. 2010, 3, 512-512.

14. Krebs, F. C.; Tromholt, T.; Jørgensen, M. Upscaling of Polymer Solar Cell Fabrication Using Full Roll-to-Roll Processing. Nanoscale 2010, 2, 873-886.

15. Alstrup, J.; Medford, A. J.; Jørgensen, M.; Krebs, F. C. Ultrafast and Parsimonious Materials Screening for Polymer Solar Cells Using Differentially Pumped Slot-Die Coating. ACS Appl. Mater. Interfaces 2010, 2, 2819-2827.

16. ASTM INTERNATIONAL Standards Worldwide. Standard Test Methods for Measuring Adhesion by Tape Test. p. 8.

17. Renner, R. Growing Concern over Perfluorinated Materials. Environ. Sci. Technol. 2001, 35, 154A-160A.

18. Yoneda, Y. Anomalous Surface Reflection of X-Rays. Phys. Rev. 1963, 131, 2010-2013.

19. Apitz, D.; Bertram, R.; Benter, N.; Hieringer, W.; Andreasen, J.; Nielsen, M.; Johansen, P.; Buse, K. Investigation of Chromophore-Chromophore Interaction by Electro-optic Measurements, Linear Dichroism, X-ray Scattering, and Density-Functional Calculations. Phys. Rev. E 2005, 72, 036610-1-036610-10.

20. Breiby, D. W.; Bunk, O.; Andreasen, J. W.; Lemke, H. T.; Nielsen, M. M. Simulating X-ray Diffraction of Textured Films. J. Appl. Crystallogr. 2008, 41, 262-271.

21. Villarrubia, J. Algorithm for Scanned Probe Microscope Image Simulation, Surface Reconstruction, and Tip Estimation. J. Res. Natl. Inst. Stand. Technol. 1997, 102, 425-454.

22. Hoo, C. M.; Starostin, N.; West, P.; Mecartney, M. L. A Comparison of Atomic Force Microscopy (AFM) and Dynamic Light Scattering (DLS) Methods to Characterize Nanoparticle Size Distributions. J. Nanopart. Res. 2008, 10, 89-96.

23. Boyd, R. D.; Cuenat, A. New Analysis Procedure for Fast and Reliable Size Measurement of Nanoparticles from Atomic Force Microscopy Images. J. Nanopart. Res. 2011, 13, 105-113.

24. Dias, A.; Buono, V. T. L.; Vilela, J. M. C.; Andrade, M. S.; Lima, T. M. Particle Size and Morphology of Hydrothermally Processed MnZn Ferrites Observed by Atomic Force Microscopy. J. Mater. Sci.: Mater. Med. 1997, 32, 47154718.

25. Krebs, F. C.; Søndergaard, R.; Jørgensen, M. Printed Metal Back Electrodes for R2R Fabricated Polymer Solar Cells Studied Using the LBIC Technique. Sol. Energy Mater. Sol. Cells 2011, 95, 1348-1353.

26. Reese, M. O.; Gevorgyan, S. A.; Jørgensen, M.; Bundgaard, E.; Kurtz, S. R.; Ginley, D. S.; Olson, D. C.; Lloyd, M. T.; Morvillo, P.; Katz, E. A.; et al. Consensus Stability Testing Protocols for Organic Photovoltaic Materials and Devices. Sol. Energy Mater. Sol. Cells 2011, 95, 1253-1267. 